\title{
Elder abuse: a mini review
}

\begin{abstract}
There is an increasing interest in social, clinical, and public health research on elder abuse. Recent studies show a wide prevalence range of figures because studies employ different populations, measures, and definitions of abuse. The prevalence rate of elderly people abuse is between $2 \%$ and $44 \%$. It is one of the most hidden modes of interfamily conflict, and the strategies of recognition of this problem as a social and global phenomenon are still meager. The lack of adequate guidelines related to this major public health issue make it difficult to early evaluate and recognize elderly abuse, as its often confused with the aging process. For these reasons, healthcare professionals should be more aware to this issue, to screen elderly abuse and to develop strategies to early detect the risk factors for elder abuse.
\end{abstract}

Keywords: elder abuse, prevalence, risk factor
Volume 3 Issue 5 - 2017

\author{
Coralie Sandrine Alves,' Carla Serrão² \\ 'Resident in Family Medicine, Abel Salazar Institute of \\ Biomedical Sciences, Portugal \\ ${ }^{2}$ Psychologist, School of Education of the Polytechnic of Porto, \\ Portugal
}

Correspondence: Carla Serrão, School of Education of the Polytechnic of Porto, Portugal,Tel +35I 22507 3460, 35 I Fax 225073 464, Email carlaserrao@ese.ipp.pt

Received: May 29, 2017 | Published: August 30, 2017

\section{Introduction}

Only in the last three decades, elderly abuse has become a phenomenon of interest and investigative production. ${ }^{1}$ There are two main reasons: on one hand, it's a consequence of the changes of the demographic profile around the world; and on the other hand, only recently, abuse against elderly people has been considered as a major public health issue. ${ }^{2}$ Elder abuse is defined by the World Health Organization (WHO) as "a single or repeated act, or lack of appropriate action, occurring within any relationship where there is an expectation of trust, which causes harm or distress to an older person". ${ }^{3}$ Is generally divided into the following categories: "physical abuse - the infliction of pain or injury, physical coercion, or physical or drug induced restraint; psychological or emotional abuse-the infliction of mental anguish; financial or material abuse-the illegal or improper exploitation or use of funds or resources of the older person; sexual abuse-non-consensual sexual contact of any kind with the older person; neglect-the refusal or failure to fulfil a caregiving obligation. This may or may not involve a conscious and intentional attempt to inflict physical or emotional distress on the older person". ${ }^{4}$ The first population-based epidemiological survey on the phenomenon of elder abuse was conducted in the United States in 1988. ${ }^{5}$ However, only more recently this problem has been subjected to further investigation. For example, Dong, ${ }^{6}$ concluded in his systematic review that in North and South America, the prevalence of elder abuse was $10 \%$; in Europe, ranged from $2.2 \%$, in Ireland to $24,25 \%$, in Croatia; and on the African continent, the prevalence ranged from $30 \%$ to $43.7 \%$. In the systematic review conducted by Santos et al., ${ }^{7}$ the overall prevalence rates of elder abuse, founded in population-based studies, ranged from $0.8 \%$ (in Spain) to $18.4 \%$ (in Israel).

Regarding the vulnerability or risk factors analyzed by different studies, it is shown that elder abuse is more common in minority communities, ${ }^{6}$ namely the female sex, people who are 75 years old or more, and elder people who suffered loss of autonomy, mental health and live with family members. ${ }^{7}$ The consequences of this abuse can be especially serious, because the elder population is "physically weaker and more vulnerable than younger adults, their bones are more brittle and convalescence takes longer. Even a relatively minor injury can cause serious and permanent damage". ${ }^{4}$

The actual data on elder abuse are still incipient and with inconsistent results. This seems to be one of the most hidden family conflicts, and the recognition strategies of this problem as a social and global phenomenon are still scarce. ${ }^{8}$ However, the lack of adequate guidelines related to this issue makes it difficult to recognize the existence of elder abuse, often confused with situations linked to normal aging (skin fragility, osteoporosis fracture, poor wound healing), or underlying diseases which the elderly person presents (anorexia due to mental illness, complications related to decompensated Diabetes Mellitus). ${ }^{9}$ In addition, there is no consensus on the theme or evidence of the risk factors screening for the occurrence of elder abuse concerning the community. ${ }^{7,9,10}$

Finally, and due to the factors previously explored, there is also a lack of structured networks, (national, international and multi professional) for the screening of elder abuse, and a lack of complaint by the victims or professionals, this way leading to an underreporting of those cases. ${ }^{8-10}$ For this reason, it is urgent to raise awareness and teach healthcare professionals on screening of possible situations of elder abuse, using screening questionnaires or scales and making a systematic and holistic evaluation of the elderly person who has risk factors for abuse. Prevention starts with awareness, through education and training. ${ }^{4}$ Finally, the assertive recognition of elder abuse risks is a major role of healthcare professionals who must refer and/or develop a safety plan and provide detailed information to help the elderly to overcome the situation, to safeguard their right to dignity and to protect their full exercise of their human rights. ${ }^{3,6,8-10}$

\section{Acknowledgements}

None.

\section{Conflict of interest}

The author declares that there is no conflict of interest.

\section{References}

1. Krug EG, Dahlberg LL, Mercy JA, et al. World report on violence and health. Geneva, Switzerland: World health organization; 2002.

2. Barnett OW, Miller-Perrin CL, Perrin RD. History and definitions. In: Barnett $\mathrm{O}$, Miller-Perrin C, editors. Family violence across the lifespan: an introduction. London, United Kingdom: Sage Publications; 1997. p. $3-17$. 
3. WHO. Active Ageing. A Policy Framework. Geneva, Switzerland: World health organization; 2002.

4. World health organization. World report on violence and health. Geneva, Switzerland: World health organization; 2002.

5. Pillemer K, Finkelhor D. The prevalence of elder abuse: a random sample survey. Gerontologist. 1988;28(1):51-57.

6. Dong XQ. Elder abuse: systematic review and implications for practice. $J$ Am Geriatr Soc. 2015;63:1214-1238.
7. Santos AJ, Nicolau R, Fernandes AA, et al. Prevalência da violência contra pessoas idosas-Uma revisão critica da literatura. Sociologia, problemas e práticas. 2013;72:53-77.

8. Podnieks E, Anetzberger GJ, Wilson SJ, et al. Worldview environmental scan on elder abuse. J Elder Abuse Negl. 2010;22(1-2):164-179.

9. Hoover RM, Polson M. Detecting elder abuse and neglect: Assessment and intervention. Am Fam Physician. 2014;89(6):453-460.

10. Yaffe MJ, Tazkarji B. Understanding elder abuse in family practice. Can Fam physician. 2012;58(12):1336-1340. 